\title{
Hypothalamic $\boldsymbol{\kappa}$-Opioid Receptor Modulates the Orexigenic Effect of Ghrelin
}

\author{
Amparo Romero-Picó', Maria J Vázquez', David González-Touceda', Cintia Folgueira', Karolina P Skibicka ${ }^{2}$, \\ Mayte Alvarez-Crespo ${ }^{2}$, Margriet A Van Gestel ${ }^{3}$, Douglas A Velásquez', Christoph Schwarzer ${ }^{4}$, \\ Herbert Herzog ${ }^{5}$, Miguel López', Roger A Adan ${ }^{3}$, Suzanne L Dickson ${ }^{2}$, Carlos Diéguez ${ }^{*, 1}$ and \\ Rubén Nogueiras*,
}

'Department of Physiology, School of Medicine-CIMUS — Instituto de Investigaciones Sanitarias (IDIS), CIBER Fisiopatologia de la Obesidad y Nutricion (CIBERobn), San Francisco s/n, Santiago de Compostela (A Coruña), University of Santiago de Compostela, Santiago de Compostela, Spain; '2Department of Physiology, Institute of Neuroscience and Physiology, The Sahlgrenska Academy, University of Gothenburg, Gothenburg, Sweden; ${ }^{3}$ Department of Neuroscience and Pharmacology, Rudolf Magnus Institute of Neuroscience, University Medical Center Utrecht, Utrecht, The Netherlands; ${ }^{4}$ Department of Pharmacology, Innsbruck Medical University, Innsbruck, Austria; ${ }^{5}$ Neuroscience Program, Garvan Institute of Medical Research, St Vincent's Hospital, Sydney, Australia

\begin{abstract}
The opioid system is well recognized as an important regulator of appetite and energy balance. We now hypothesized that the hypothalamic opioid system might modulate the orexigenic effect of ghrelin. Using pharmacological and gene silencing approaches, we demonstrate that ghrelin utilizes a hypothalamic $\kappa$-opioid receptor (KOR) pathway to increase food intake in rats. Pharmacological blockade of KOR decreases the acute orexigenic effect of ghrelin. Inhibition of KOR expression in the hypothalamic arcuate nucleus is sufficient to blunt ghrelin-induced food intake. By contrast, the specific inhibition of KOR expression in the ventral tegmental area does not affect central ghrelin-induced feeding. This new pathway is independent of ghrelin-induced AMP-activated protein kinase activation, but modulates the levels of the transcription factors and orexigenic neuropeptides triggered by ghrelin to finally stimulate feeding. Our novel data implicate hypothalamic KOR signaling in the orexigenic action of ghrelin.

Neuropsychopharmacology (2013) 38, 1296-1307; doi:I0.1038/npp.2013.28; published online I3 February 2013
\end{abstract}

Keywords: hypothalamus; food intake; ghrelin; opioid receptor

\section{INTRODUCTION}

The central regulation of food intake is a highly complex process involving diverse brain areas. Both homeostatic and hedonic systems drive feeding behavior in order to ensure an adequate nutrient supply (Johnstone et al, 2006; Saper et al, 2002). Ghrelin, a circulating orexigenic hormone mainly produced in the stomach, activates both homeostatic and hedonic mechanisms (Skibicka and Dickson, 2011a), effects mediated via the growth hormone secretagogue receptor (GHS-R1A). At the hypothalamic level, ghrelin increases the expression of neuropeptide $\mathrm{Y}$ (NPY) and agouti-related peptide (AgRP) in the ARC. To activate orexigenic NPY/AgRP neurons, ghrelin requires the

*Correspondence: Professor C Dieguez, CIBER 'Fisiopatología de la Obesidad y Nutrición', Instituto de Salud Carlos III, Santiago de Compostela (A Coruña), Spain, Tel: + 34 881 815437, Fax: + 34 981 574|45, E-mail: carlos.dieguez@usc.es or Dr R Nogueiras, Department of Physiology, School of Medicine, University of Santiago de Compostela-Instituto de Investigación Sanitaria, S. Francisco s/n, Santiago de Compostela (A Coruña) 15782, Spain. E-mail: ruben.nogueiras@usc.es Received 7 August 2012; revised 30 November 2012; accepted 2 January 2013; accepted article preview online 24 January 2013
AMP-activated protein kinase (AMPK) pathway (Kola et al, 2005; Lopez et al, 2008). GHS-R1A is also expressed at extra-hypothalamic areas such as the ventral tegmental area (VTA), one of the main brain centers involved in the hedonic/reward regulation of food intake (Saper et al, 2002). Activation of GHS-R1A at the level of the VTA induces a feeding response (Egecioglu et al, 2010; Naleid et al, 2005; Skibicka et al, 2011b), and central ghrelin signaling has recently been shown to be of importance for food reward and food motivation (Skibicka and Dickson, 2011a). However, the molecular mechanisms underpinning these food-oriented behaviors are poorly understood. Interestingly, the target neurobiological circuits for ghrelin's effects on food reward/motivation, namely the mesolimbic VTA-NAcc dopamine system (Abizaid et al, 2006; Skibicka et al, 2011b), share neurochemical overlap with those used by the opioid system to confer reward from chemical drugs of abuse. GHS-R1A is widely distributed throughout the central nervous system and is expressed in several appetite-regulating areas such as the arcuate nucleus (ARC), ventromedial hypothalamic nucleus $(\mathrm{VMH})$, paraventricular nucleus (PVH), and dorsomedial (DMH) hypothalamic nuclei, the lateral hypothalamic area (LHA), 
and in dopaminergic, cholecystokinin-containing neurons of the substantia nigra, and ventral tegmental area (Zigman et al, 2006).

The established role of the endogenous opioid system as an important regulator of appetite (Glass et al, 1999) and energy balance likely involves multiple systems and mechanisms. Stanley et al (1988) described multiple brain sites sensitive to feeding stimulation by opioid agonists, and several studies have found effects of central blockade of opioid receptors on NPY-induced feeding (Kotz et al, 1993; Lambert et al, 1993). Furthermore, studies in mice with selective knockout of the opioid receptors demonstrate the importance of $\mu-, \kappa-$, and $\delta$-opioid receptors on the metabolic response to a high-energy diet (Czyzyk et al, 2010, 2012; Tabarin et al, 2005). The importance of the opioid system in energy homeostasis has been further highlighted in different clinical trials showing the beneficial effects of opioid antagonists in combination with other therapies on body weight in obese subjects (Greenway et al, 2010). As is the case for GHS-R1A, $\kappa$-opioid receptor (KOR) is widely distributed throughout the central nervous system. These include hypothalamic areas (such as the $\mathrm{VMH}$, periventricular $(\mathrm{PeN})$, supraoptic (SO), ARC, and $\mathrm{DMH})$, and also in extra-hypothalamic areas (that include, among others, the substantia nigra and ventral tegmental (VTA)) (DePaoli et al, 1994).

Several reports have sought to identify the role of opioids in the orexigenic effects of central ghrelin administration. For instance, the general opioid antagonist, naltrexone, injected into the nucleus accumbens (NAc) did not affect feeding elicited by ghrelin injection into the VTA, and naltrexone in the VTA did not affect feeding elicited by ghrelin injected into the NAc (Naleid et al, 2005). Additionally, there are indication that some of the central pharmacological actions of ghrelin are opioid mediated such as pain (Sibilia et al, 2006) and pulsatile luteinizing hormone secretion (Ogata et al, 2009).

In spite of recent findings uncovering the molecular mechanisms mediating the orexigenic action of ghrelin, it is unknown whether the hypothalamic opioid system is involved in ghrelin's effects to regulate food intake. Therefore, in the present study, we aimed to determine: (1) if the hypothalamic opioid system modulates the orexigenic effect of ghrelin and (2) the potential neuronal and molecular mechanisms involved in the interaction between the opioid and ghrelin systems. This study is the first to implicate hypothalamic KOR in the homeostatic regulation of food intake mediated by ghrelin.

\section{MATERIALS AND METHODS}

\section{Animal Procedures and Chemicals}

Male Sprague-Dawley rats were housed individually and maintained on a 12:12-h light-dark cycle. They were allowed ad libitum access to water and standard chow from Scientific Animal Food \& Engineering (proteins 16\%, carbohydrates $60 \%$, and fat $3 \%$ ). Rats were anesthetized by an intraperitoneal injection of ketamine-xylacine (ketamine $100 \mathrm{mg} / \mathrm{kg} \mathrm{BW}+$ xylazine $15 \mathrm{mg} / \mathrm{kg} \mathrm{BW).} \mathrm{Intra-}$ cerebroventricular (i.c.v.) cannulae aimed at the lateral ventricle were implanted stereotaxically as described previously (Nogueiras et al, 2007; Skibicka et al, 2011c). All of the tests were performed at the beginning of the light phase. Animals were killed by decapitation. All animal procedures were conducted in accordance with the standards approved by the Faculty Animal Committee at the University of Santiago de Compostela and at the University of Gothenburg, and the experiments were performed in agreement with the Rules of Laboratory Animal Care and International Law on Animal Experimentation.

Acetylated rat ghrelin was purchased from Bachem (Bubendorf, Switzerland, experiments 1-5) or Tocris (St Louis, MO, USA, experiment 5). All opioid receptor inhibitors: naloxone (a non-selective opioid receptor antagonist), $\beta$-FNA ( $\mu$-opioid receptor antagonist), naltrindole ( $\delta$-opioid receptor antagonist), and norBNI (KOR antagonist) were purchased from Tocris (St Louis, MO, USA), and the $\kappa$-opioid agonist DAMGO was purchased from Sigma (USA).

\section{Experiment 1: Impact of i.c.v. Administration of Opioid Receptor Antagonists on i.c.v. Ghrelin-Induced Food Intake}

To study the effect of opioid receptor antagonists on ghrelin-induced food intake, rats were fed ad libitum and four different groups were tested: (1) vehicle/vehicle, (2) vehicle/ghrelin, (3) antagonist/vehicle, (4) antagonist/ghrelin $(n=10-20$ rats per group). The opioid receptor antagonists were administered i.c.v. 20 min before i.c.v. ghrelin injection, and food intake was measured $2 \mathrm{~h}$ later. The antagonists were administered at dose of: 30 and $60 \mu \mathrm{g}$ (75 and $150 \mathrm{nmol}$ ) (naloxone); 5 and $30 \mu \mathrm{g}$ (10.2 and $61.2 \mathrm{nmol})(\beta$-FNA); 15 and $30 \mu \mathrm{g}(20$ and $40 \mathrm{nmol})$ (norBNI); and $40 \mu \mathrm{g}(83.8 \mathrm{nmol})$ (naltrindole). We injected $5 \mu \mathrm{g}(1.5 \mathrm{nmol})$ of ghrelin. The vehicle for delivery and control injections was saline ( $5 \mu$ l i.c.v. over $1 \mathrm{~min})$.

\section{Experiment 2: Impact of Intra-VTA Administration of a} KOR Antagonist on Ghrelin-Induced Food Intake

Bilateral guide cannulae were positioned and secured to the skull for subsequent drug injection via an internal catheter (PlasticsOne, C235G-2.0 7.9 mm and C235I/0.5 mm projection). The stereotaxic coordinates were: $\pm 1 \mathrm{~mm}$ from the midline, $5.5 \mathrm{~mm}$ posterior to bregma, and $7.8 \mathrm{~mm}$ ventral from the surface of the skull. Four groups of rats fed ad libitum were tested: (1) vehicle/vehicle, (2) vehicle/ghrelin, (3) norBNI/vehicle, (4) norBNI/ghrelin. Ghrelin $(2 \mu \mathrm{g})$ and norBNI $(4 \mu \mathrm{g})$ were administrated bilaterally into the VTA as described previously (Naleid et al, 2005; Ragnauth et al, 1997). norBNI was injected into the VTA 20 min before ghrelin administration and food intake was measured at $2 \mathrm{~h}$ after the ghrelin injection. The vehicle for delivery and control injections was saline ( $2 \mu \mathrm{l}$ intra-VTA over $1 \mathrm{~min}$ ).

Experiments 3-4: Impact of Oprk Silencing in the ARC or VTA on i.c.v. Ghrelin-Induced Food Intake

We injected bilaterally $1 \mu \mathrm{l}$ of adeno-associated viral (AAV) vectors $\left(1 \times 10^{9}\right.$ genomic copies per $\left.1 \mu \mathrm{l}\right)$ encoding or not rat opioid receptor $\kappa$ short-hairpin RNAs (shRNA) to 
specifically silence the expression of Oprk1 mRNA in the ARC or the VTA. The stereotaxic coordinates to reach the ARC were $\pm 0.3 \mathrm{~mm}$ from the midline, $2.8 \mathrm{~mm}$ posterior to bregma, and $10.2 \mathrm{~mm}$ ventral from the surface of the skull; and for VTA, coordinates used are described in experiment 2. Next, an i.c.v. cannula was implanted. Food intake and body weight were monitored daily during 14 days. After 2 weeks, four groups of rats fed ad libitum were tested: (1) control-vehicle, (2) control-ghrelin, (3) Oprk1 shRNAvehicle, (4) Oprk1 shRNA-ghrelin. In the experiment 4, four groups of rats were tested: (1) control-vehicle, (2) control-DAMGO, (3) Oprk1 shRNA-vehicle, (4) Oprk1 shRNA-DAMGO. Food intake was measured $2 \mathrm{~h}$ after i.c.v. administration of vehicle or ghrelin $(5 \mu \mathrm{g})$ or DAMGO $(10 \mathrm{nmol})$ in $5 \mu \mathrm{l}$ in saline vehicle.

Experiment 5: Impact of i.c.v. Administration of Opioid Receptor Antagonists on i.c.v. Ghrelin-Induced Increase in Food Reward Behavior

To determine whether KOR is necessary for the food reward/motivation actions of ghrelin, we performed a progressive ratio operant conditioning test for a sugar reward as described in Supplementary information and in previous reports (Skibicka et al, 2012).

\section{shRNA Oprk1 Design and Adeno-Associated Viruses Synthesis}

Following the Dharmacon and Invitrogen siDesigner recommendations (center web site and NCBI Reference Sequence NM_017167.2.) two sets of oligo's were used for cloning (Supplementary table 1). The oligonucleotides had $X b a \mathrm{I}$ and SapI overhangs to allow for ligation into an AAV plasmid co-expressing EGFP. The AAV serotype is AAV1 and the promoter used was U6. HEK293T cells were transfected with pAAV-shRNA and helperplasmid pDP1 (Plasmid Factory, Bielefeld, Germany) using polyethylenimine (PEI). At $60 \mathrm{~h}$ after transfection, cells were harvested pelleted and resuspended in an ice-cold buffer $(150 \mathrm{mM}$ $\mathrm{NaCl}, 50 \mathrm{mM}$ Tris, $\mathrm{pH}$ 8.4). Cells were freeze-thawed twice and incubated for $30 \mathrm{~min}$ at $37^{\circ} \mathrm{C}$ with Benzonase $(50 \mathrm{U} / \mathrm{ml}$; Sigma, Zwijndrecht, The Netherlands). The lysate was loaded onto a $15,25,40$, and $60 \%$ iodixanol gradient. The gradient was centrifuged at 70000 r.p.m. for $60 \mathrm{~min}$ at $18{ }^{\circ} \mathrm{C}$, the $40 \%$ fraction was extracted and used for ion-exchange chromatography. The AAV-positive fractions, determined by PCR, were pooled and concentrated on Centricon Plus20 Biomax-100 concentrator columns (Millipore, Amsterdam, The Netherlands). Titer (genomic copies per ml) was determined by quantitative PCR on EGFP sequence. AAV were diluted to $1 \times 10^{9}$ g.c./ $\mu \mathrm{l}$ and mixed $(1: 1)$. In all, $1 \mu \mathrm{l}$ of this mix was injected into each brain area. To design control AAV, we used shRNA that does not target anything (de Backer et al, 2010) (Supplementary Table 1).

\section{In Situ Hybridization}

We performed in situ hybridization to visualize hypothalamic mRNA expression of NPY, AgRP (Seoane et al, 2003), Bsx (Nogueiras et al, 2008), and Orexin (Lopez et al, 2000) as described previously. We optimized a protocol for detection of prodynorphin (proDyn) and Oprk1 mRNAs. In this case, dry sections were exposed for 7-9 days (proDyn), and 30 days (Oprk1). Probes selected for detection of different mRNAs were depicted in Supplementary Table 2. Details regarding the quantification of in situ hybridization are enclosed in Supplementary Information.

\section{Western Blotting}

Total proteins were extracted from the whole hypothalamus as previously described (Velasquez et al, 2011). Dilutions of primary antibodies were 1:1000. Rabbit anti FoXO1, pCREB, and pAMPK were purchased by Cell Signaling (Danvers, MA, USA), rabbit anti pACC from Upstate (Temecula, CA, USA), and mouse anti- $\beta$-Actin, rabbit anti-opioid receptor $\delta$, goat anti-opioid receptor $\kappa$ from Sigma Aldrich (USA), and rabbit anti-opioid receptor $\mu$ from Abcam (Cambridge, UK). Secondary antibodies were purchased by Dako and used at dilution 1:5000 in 3\% BSA in TBS-T $0.1 \%$. Detection was performed using enhanced chemiluminescence reagent (Amersham Biosciences, Little Chalfont, UK).

\section{Immunohistochemistry and Immunofluorescence}

Paraffin-embedded coronal brain sections $(4 \mu \mathrm{m})$ were dried overnight at $55-60{ }^{\circ} \mathrm{C}$, de-paraffined with xylene and then rehydrated. Antigenic recuperation was performed using citrate buffer $10 \mathrm{mM} \mathrm{pH}=6$ and 800 watts pulses $(2 \times 10 \mathrm{~min})$. For immunohistochemistry, sections were incubated with primary antibodies overnight at $4{ }^{\circ} \mathrm{C}$ with rabbit anti-proDyn $(1: 1000)$ (Abcam) diluted in EnVision Flex Antibody diluent (Dako). Sections were then incubated with secondary antibody for $30 \mathrm{~min}$, using Dako Real Envision HRP to detect rabbit or mouse, and LSAB + System-HRP to detect goat. Visualization involved reaction with diaminobenzidine and counterstaining with hematoxilin, before mounting (Eukit, Labolan) and coverslipping.

For co-localization studies, after antigenic recuperation, sections were treated with $50 \mathrm{mM}$ ammonium chloride for $1-2 \mathrm{~h}$ and were then incubated with primary antibody (overnight at $4{ }^{\circ} \mathrm{C}$ ) at dilutions 1:500 (goat anti-GHS-R1A, Santa Cruz), and 1:1500 (rabbit anti-KOR, Acris). This was followed by $1 \mathrm{~h}$ incubation with the secondary antibody: donkey anti-rabbit Alexa594, anti-mouse Alexa488 (Invitrogen), or anti-goat Cy2 (Jackson ImmunoResearch). Sections were mounted with Fluoro-Gel (Aname). Images were captured in a Confocal Microscopy Leica TCS-SP2.

\section{RNA Isolation and Real-Time RT-PCR}

The efficiency of Oprk silencing expression in vivo was determined by real-time RT-PCR. The brain was removed and placed in a brain matrix with a ventral surface on top under a dissecting microscope. The ARC was removed from the whole hypothalamus by cutting between the rostral and caudal limits of the median eminence parallel to the base of the hypothalamus and $0.5 \mathrm{~mm}$ to each lateral side of the median eminence. The depth of each section isolated was around $1 \mathrm{~mm}$ thick. To remove the VTA, a $1-\mathrm{mm}$ thick slice was cut between 5.2 and $6.2 \mathrm{~mm}$ posterior to bregma, and 
$1.5 \mathrm{~mm}$ from the middle line. The depth of VTA section was $\sim 1.5 \mathrm{~mm}$. Total ARC or VTA RNA was extracted and realtime PCR was performed as described previously (Lopez et al, 2010). Primers and probes sequences are described in Supplementary Table 3.

\section{Statistical Analysis and Data Presentation}

The results are expressed as mean values \pm SEM. GraphPad Prism (4.0) and $\mathrm{R}$ version 2.15.1. were used for the data analysis. Two-way ANOVA was used to examine interactions between variables (pre-treatment with norBNI or Oprk silencing by iRNA $\times$ ghrelin). Three-way ANOVA was used to identify antagonist subtype $\times$ antagonist dose $\times$ ghrelin interactions. Direct comparisons between two groups were performed using an unpaired $t$-test. Sample sizes and statistical tests used are defined in each figure legend.

\section{RESULTS}

\section{KOR and Ghrelin Receptor Co-localize in Brain Areas Involved in Energy Balance Regulation}

The expression and localization of opioid receptors in rat brain have been described previously (Arvidsson et al, 1995; Mansour et al, 1994). In agreement with previous studies, our in situ hybridization results also showed a clear mRNA expression of Oprk1 in the ARC, VMH, PVH, and VTA (Supplementary Figure 1A-D). As GHS-R1A, immunofluorescence analysis corroborated that KOR protein was also located in these brain areas (Figure 1a-i). Double-labeling studies showed that $73 \%$ of cells expressing GHS-R1A colocalize with $\mathrm{KOR}$ in the ARC, $80 \%$ in $\mathrm{VMH}$, and $69 \%$ in VTA (Figure 1j).

\section{Central KOR Inhibition Impairs Ghrelin-Induced Food Intake in an AMPK-Independent Manner}

As expected, ghrelin increased food intake compared with control group (vehicle) during the 2 -h period post-injection (Figure 1k; Supplementary Figure 2A-C). To study a potential interaction between the opioid system and the orexigenic effect of ghrelin, we pre-treated rats with different doses of opioid receptor antagonists and measured ghrelininduced food intake $2 \mathrm{~h}$ later. Pharmacological blockade using the generic opioid receptor antagonist naloxone did not impair the orexigenic effect of ghrelin $(P<0.0001$, $\mathrm{F}=156.3, \mathrm{DF}=1)$. We did not observe naloxone $\times$ naloxone dose $\times$ ghrelin interaction $(p$ naloxone:ghrelin $=0.19, \mathrm{~F}=1.738$, $\mathrm{DF}=1$ ) (Supplementary Figure $2 \mathrm{~A})$. We obtained similar results with $\beta$-FNA ( $p_{\beta \text {-FNA:ghrelin }}=0.206, \mathrm{~F}=1.627, \mathrm{DF}=1$; $\left.p_{\text {ghrelin }}<0.0001, \quad \mathrm{~F}=127.084, \quad \mathrm{DF}=1\right)$ and naltrindole $\left(p_{\text {naltrindole:ghrelin }}=0.185, \mathrm{~F}=1.917, \mathrm{DF}=1 ; p_{\text {ghrelin }}<0.0001\right.$, $\mathrm{F}=37, \mathrm{DF}=1)$ (Supplementary Figure $2 \mathrm{~B}$ and $\mathrm{C})$. Blockade of KOR with norBNI significantly decreased ghrelin-induced food intake $\left(p_{\text {norBNI:ghrelin }}<0.0001, \quad \mathrm{~F}=36.872, \mathrm{DF}=1\right.$; $p_{\text {norBNI }}<0.0001, \quad \mathrm{~F}=41.871, \quad \mathrm{DF}=1 ; \quad p_{\text {ghrelin }}<0.0001$, $\mathrm{F}=149.417, \mathrm{DF}=1 ; p_{\text {dose:ghrelin }}=0.068, \mathrm{~F}=3.421, \mathrm{DF}=1$ ) (Figure 1k). Since previous reports have indicated that norBNI also has some affinity for $\mu$ - and $\delta$-opioid receptors (Horan et al, 1992), we measured ghrelin-induced food intake after i.c.v. administration of norBNI in wild-type
(WT) and KOR mutant mice. As described for rats, norBNI i.c.v. attenuated ghrelin-induced food intake in WT mice (Figure 11). However, norBNI i.c.v. did not decrease ghrelininduced food intake in KOR mutant mice (Figure 11), indicating that any potential actions of norBNI on $\mu$ - and $\delta$ opioid receptors at $2 \mathrm{~h}$ are not relevant in the regulation of the orexigenic action of ghrelin. We next examined conditioned taste aversion to identify a potential aversive response associated with norBNI, and failed to find an aversive behavior in rats treated with norBNI (Figure $1 \mathrm{~m}$ ).

Ghrelin increased hypothalamic phosphorylated levels of AMPK and ACC (Figure 1n). Unexpectedly, the phosphorylation of these two proteins remained significantly upregulated after the pharmacological inhibition of KOR (using norBNI) even though food intake was decreased (Figure 1k). Next, we assessed the levels of downstream hypothalamic factors modulating the orexigenic effect of ghrelin. Hypothalamic levels of the transcription factors phosphorylated cAMP response element-binding (pCREB), forkhead box protein $\mathrm{O} 1$ (FoxO1), and brain-specific homeobox transcription factor (Bsx) increases $2 \mathrm{~h}$ after i.c.v. ghrelin administration. When the KOR antagonist was co-administered with ghrelin, we observed a reduction in the expression of transcription factors known to be stimulated by ghrelin. More specifically, we obtained a significant interaction norBNI:ghrelin for pCREB $\left(p_{\text {interaction }}=0.0259, \quad \mathrm{~F}=5.38, \quad \mathrm{DF}=1\right) \quad$ and $\mathrm{Bsx}$ $\left(p_{\text {interaction }}=0.0069, \mathrm{~F}=8.57, \mathrm{DF}=1\right) \quad($ Figure $1 \mathrm{n}$ and $\mathrm{o}$; Supplementary Figure 3).

Next, the mRNA expression of ARC NPY and AgRP was assessed by in situ hybridization. As shown previously (Wren et al, 2000), ghrelin administration led to a significant increase of NPY ( $\left.p_{\text {ghrelin }}=0.0049\right)$, and $A g R P$ $\left(p_{\text {ghrelin }}=0.0056\right)$. However, the increased levels of NPY and AgRP observed with ghrelin treatment were not observed in rats treated with norBNI/ghrelin (Figure 10; Supplementary Figure 3) obtaining a significant decrease after norBNI administration for NPY mRNA expression $\left(p_{\text {norBNI }}=0.0068\right)$. These results indicate that independently of the ghrelin-activated PAMPK pathway, KOR is an important player modulating the ghrelin-stimulated BsxpCREB-NPY pathway.

\section{Ghrelin Stimulates Prodynorphin Levels in ARC and PVH}

Since proDyn-derived peptides are endogenous ligands of KOR (Chavkin et al, 1982; Morley and Levine, 1983), we assessed if proDyn gene expression was induced by ARC i.c.v. ghrelin administration. By in situ hybridization, we found that hypothalamic proDyn mRNA expression in the ARC and PVH was significantly upregulated in rats treated with ghrelin $\left(p_{\text {ghrelin }}=0.0028, \mathrm{~F}=11.06, \mathrm{DF}=1\right.$ in $\mathrm{ARC}$; $p_{\text {ghrelin }}=0.0033, \mathrm{~F}=11.46, \mathrm{DF}=1$ in $\mathrm{PVH}$ ) (Figure 2a). These results suggest that the upregulation of proDyn induced by ghrelin is upstream of KOR signaling. Hypothalamic VMH and LHA prodyn gene expression remained unaltered (Figure 2a). In accordance with the gene expression data, protein levels of proDyn were increased in hypothalamic ARC and PVH from rats at $2 \mathrm{~h}$ after an i.c.v. injection of ghrelin (Figure 2b). 

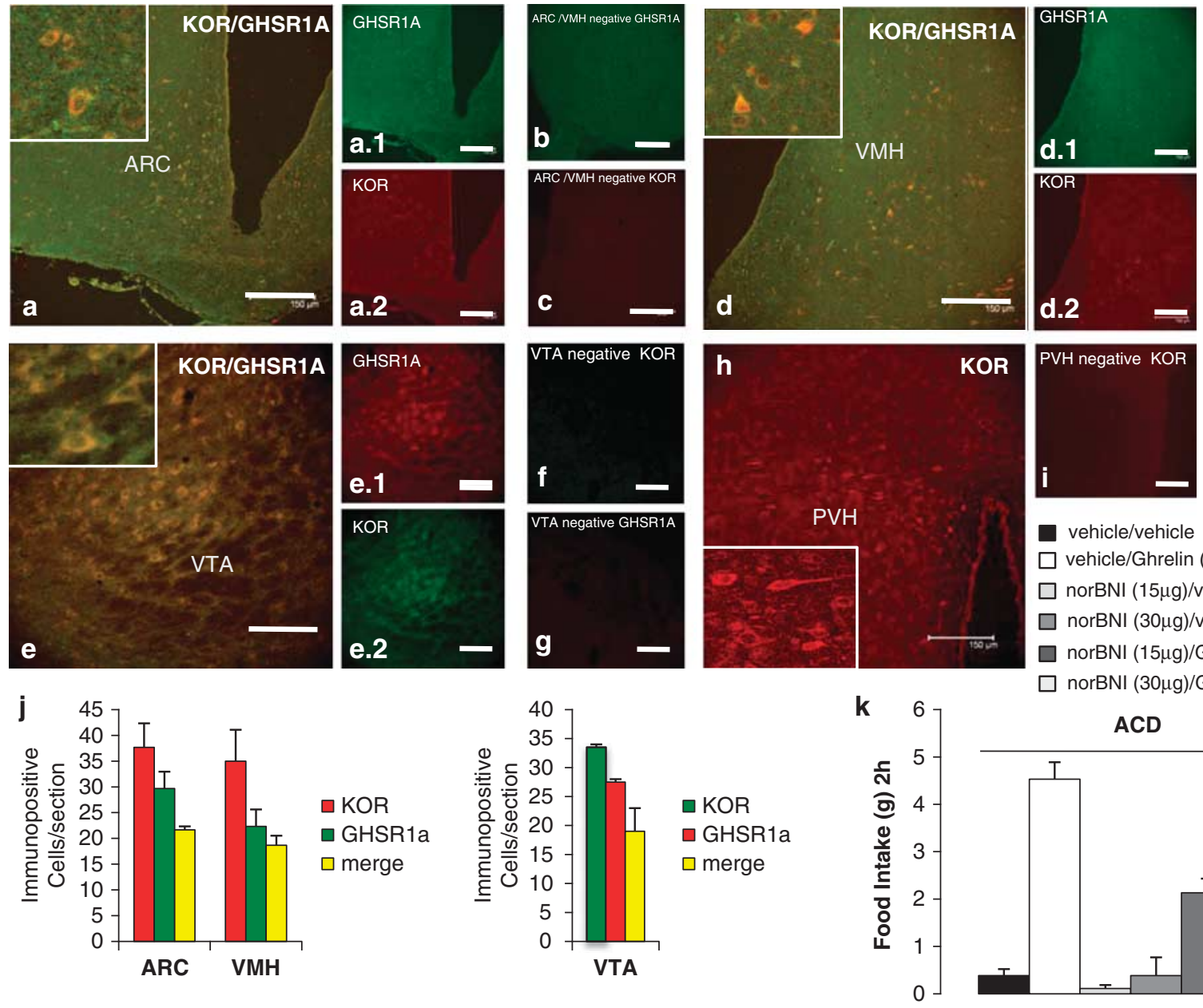

vehicle/vehicle

$\square$ vehicle/Ghrelin $(5 \mu \mathrm{g})$

$\square$ norBNI $(15 \mu \mathrm{g}) /$ vehicle

$\square$ norBNI $(30 \mu \mathrm{g}) /$ vehicle

$\square$ norBNI $(15 \mu \mathrm{g}) /$ Ghrelin

$\square$ norBNI $(30 \mu \mathrm{g}) /$ Ghrelin
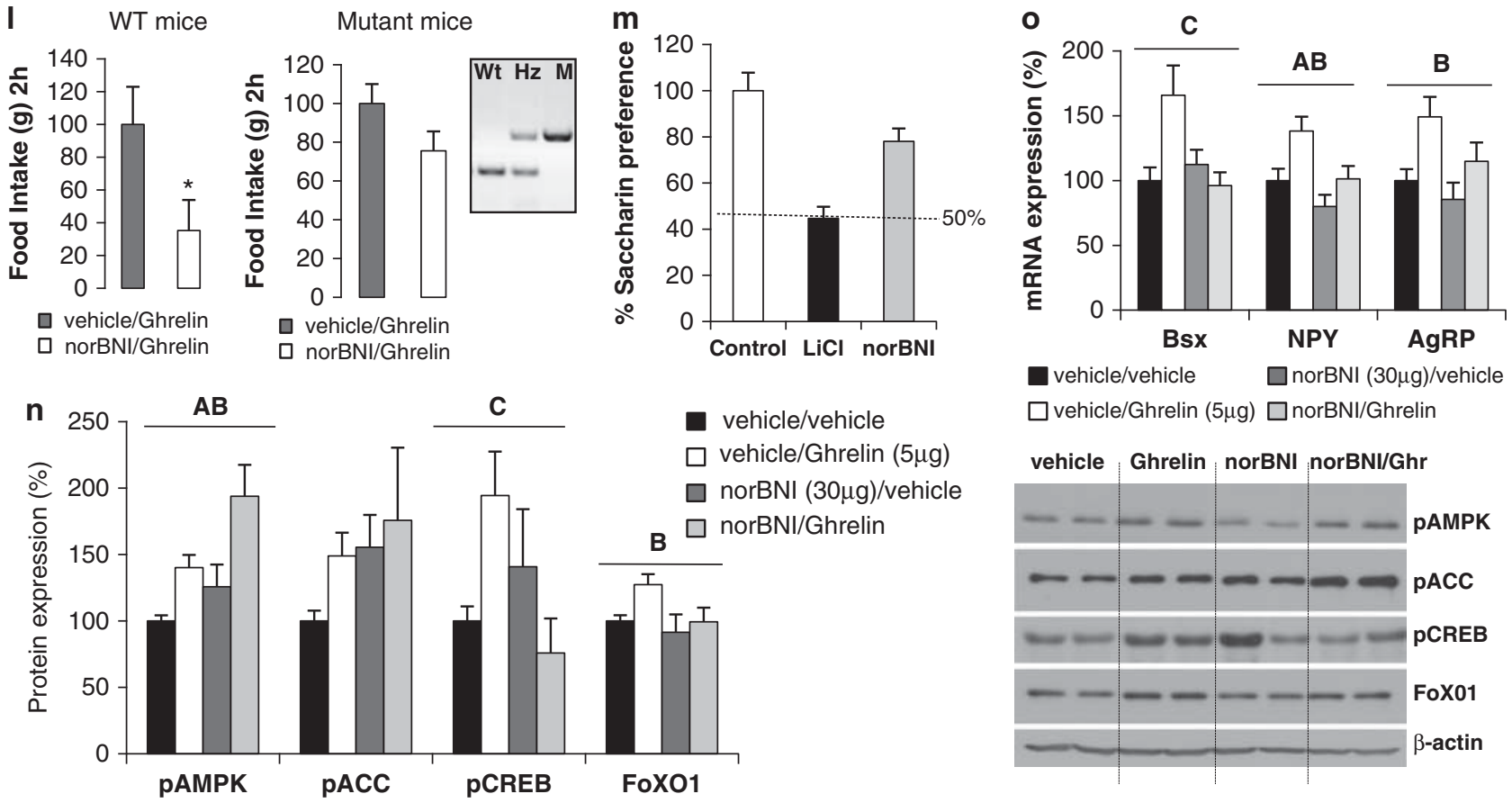

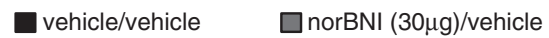

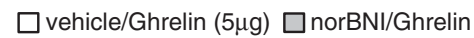
vehicle Ghrelin norBNI norBNI/Ghr

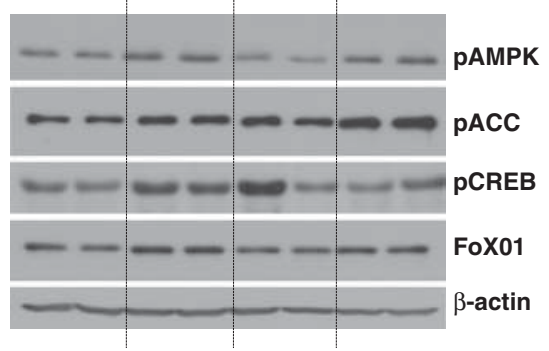


a

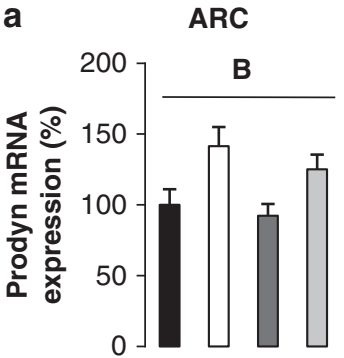

LHA

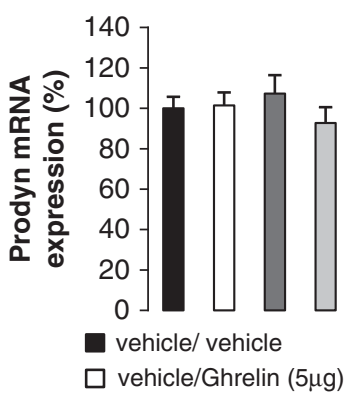

b
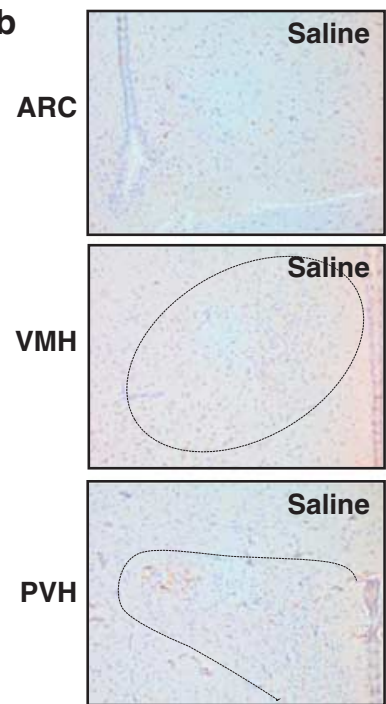
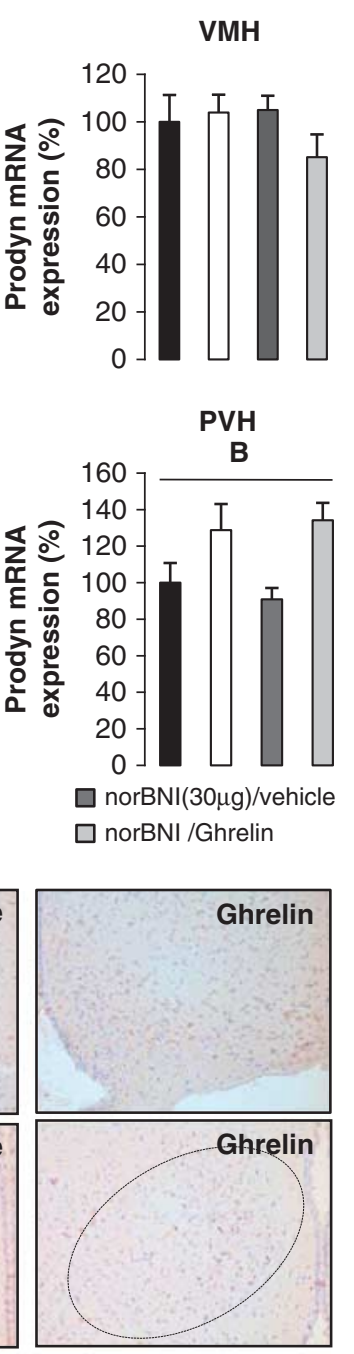

Ghrelin

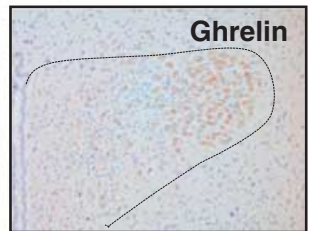

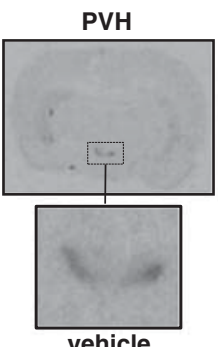
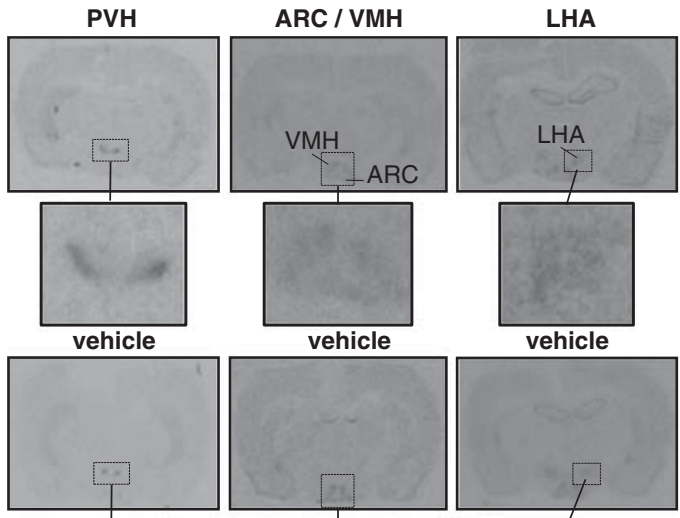

vehicle
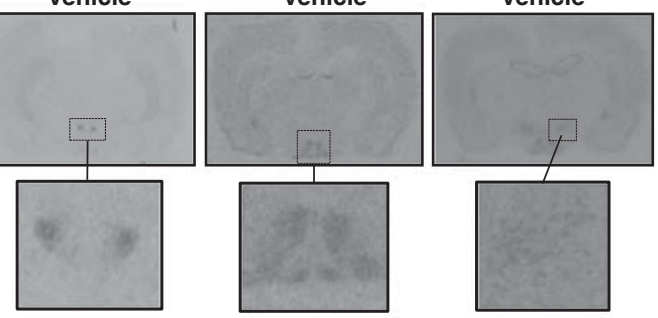

Ghrelin

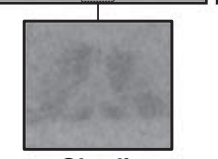

Ghrelin
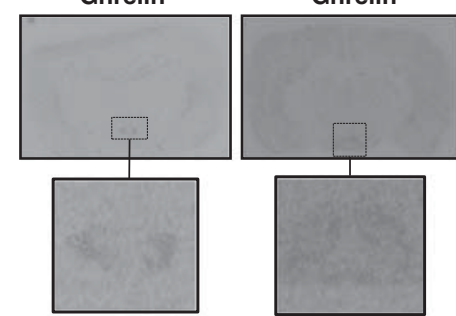

norBNI
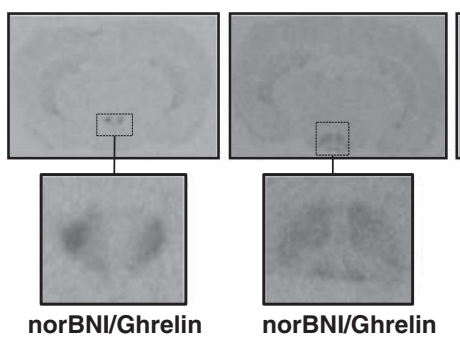

norBNI/Ghrelin

norBNI/Ghrelin

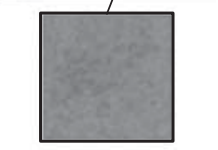

Ghrelin
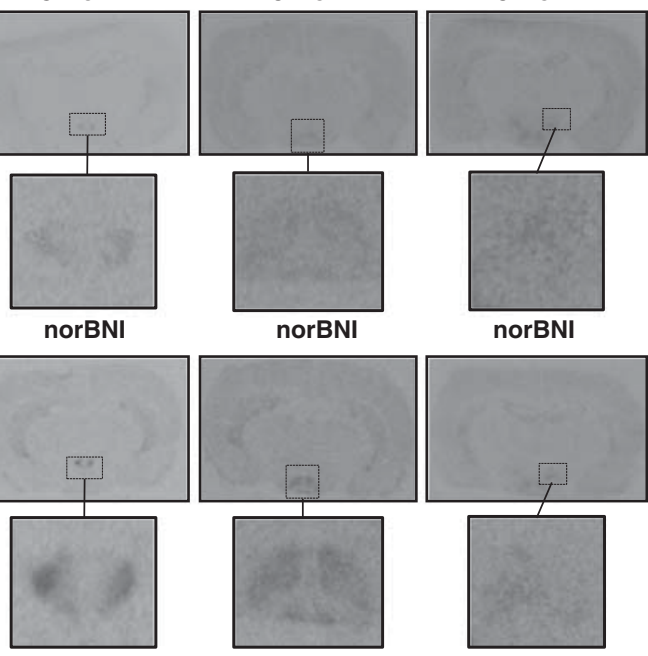

norBNI
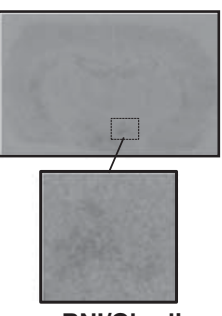

norBNI/Ghrelin

Figure 2 Ghrelin's effect on proDyn expression in hypothalamus. (a) mRNA proDyn expression in ARC, VMH, LHA, and PVH in rats treated i.c.V. with vehicle, ghrelin $(5 \mu \mathrm{g})$, norBNI $(30 \mu \mathrm{g})$, norBNI/ghrelin at $2 \mathrm{~h}$ (a). $n=8$ per group. Histograms represent mean $\pm \mathrm{SEM}$. B denotes significant effect of ghrelin $(P<0.0 \mathrm{I}$ in $\mathrm{PVH}$ and $\mathrm{P}<0.0 \mathrm{I}$ in ARC) using two-way ANOVA. (b) Immunohistochemistry analysis of proDyn expression and localization in ARC, VMH, and $\mathrm{PVH}$ in rats i.c.v. treated with saline and ghrelin at $2 \mathrm{~h}$ ( $n=4$ per group, experiment repeated twice).

Figure I Effect of $\kappa$-opioid receptor antagonist on ghrelin-induced orexigenic response. (a-i) Immunofluorescence detection of KOR protein (a.2, d.2, e.2, h) and co-localization with GHS-RIA expression in hypothalamic areas involved in food intake such as the ARC (a), VMH (d), and VTA (e). Negative controls of KOR in hypothalamus (c, i) and VTA (f). Negative controls of GHS-RIA in hypothalamus (b) and VTA (g). Scale bars: I50 $\mu$ m. (j) Graphic representations providing an estimation of the degree of KOR-expressing neurons that also express GHSRIA. $n=3$ per group. (k) Food intake stimulated by ghrelin $(5 \mu$ i.c.v. $)$ at $2 \mathrm{~h}$ under i.c.v. pharmacological blockade of $\kappa$-opioid receptor antagonist norBNI at dose 15 and $30 \mu$ g. $n=10-20$ per group. Annotation indicates significant effect of $A=\operatorname{norBNI}(P<0.00 \mathrm{I}), \mathrm{B}=$ dose $(P=0.265), \mathrm{C}=$ ghrelin $(P<0.00 \mathrm{I}), \mathrm{D}=$ norBNI-ghrelin interaction $(P<0.00 \mathrm{I})$, using three-way ANOVA. (I) Genotyping of wild-type (296 bp) and $\kappa$-opioid receptor mutant mice (580 bp) and ghrelin-induced food intake after i.c.v. administration of norBNI in WT and $\kappa$-opioid receptor mutant mice. $n=6-12$ rats per group. $P<0.05 *$ using unpaired $t$-test. Data are represented as mean \pm SEM. $(m)$ Taste aversion test to identify a potential aversive response associated with the $\kappa$-opioid antagonist norBNI. $n=10$ per group. (n) Hypothalamic protein analysis of pAMPK, pACC, pCREB, and FoXOI in rats i.c.v. stimulated by ghrelin $(5 \mu \mathrm{g})$ previous injection with norBNI $(30 \mu \mathrm{g})$. $n=8-10$ per group. $A=$ norBNI, $B=$ ghrelin, $C=$ significant norBNI-ghrelin interaction. Dividing discontinuous lines indicate splicing in the figures. Error bars indicate SEM. (o) mRNA expression of transcription factor Bsx, and neuropeptides NPY and AgRP by in situ hybridization. $n=8$ per group. A = effect of norBNI, $B=$ effect of ghrelin, $C=$ significant norBNI-ghrelin interaction using two-way ANOVA. 
Direct Intra-VTA Administration of Ghrelin Stimulates Food Intake but does not Produce Changes in Hypothalamic Orexigenic Neuropeptides

Next, we tested if the hypothalamic changes caused by ghrelin and/or norBNI involve the VTA. As previously reported (Naleid et al, 2005), intra-VTA ghrelin (Figure 3a) significantly stimulated food intake $\left(p_{\text {ghrelin }}=0.0057\right.$,
$\mathrm{F}=8.528, \mathrm{DF}=1)$, whereas intra-VTA norBNI significantly decreased food intake $\left(p_{\text {norBNI }}<0.0001, \mathrm{~F}=28.2, \mathrm{DF}=1\right)$ (Figure $3 \mathrm{~b}$ ). However, the $P$-value for interaction between ghrelin and norBNI did not reach statistical significance ( $\left.p_{\text {norBNI:ghrelin }}=0.175, \mathrm{~F}=1.904, \mathrm{DF}=1\right)$ (Figure $3 \mathrm{~b}$ ). When we measured the mRNA expression of hypothalamic neuropeptides implicated in energy balance control, we did not observe any differences in NPY or AgRP in the ARC

a
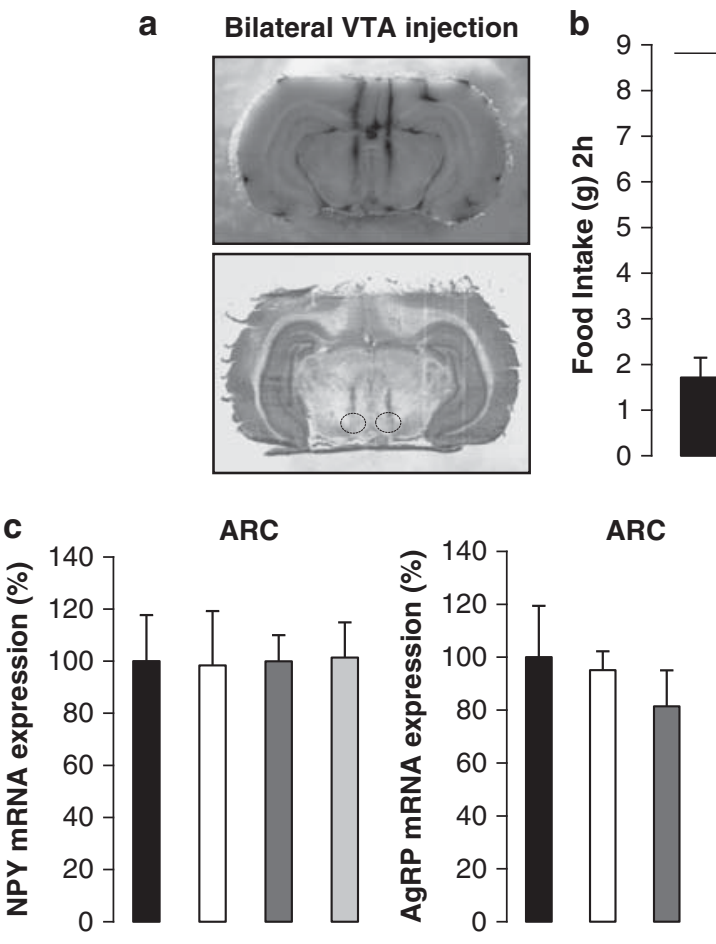

ARC
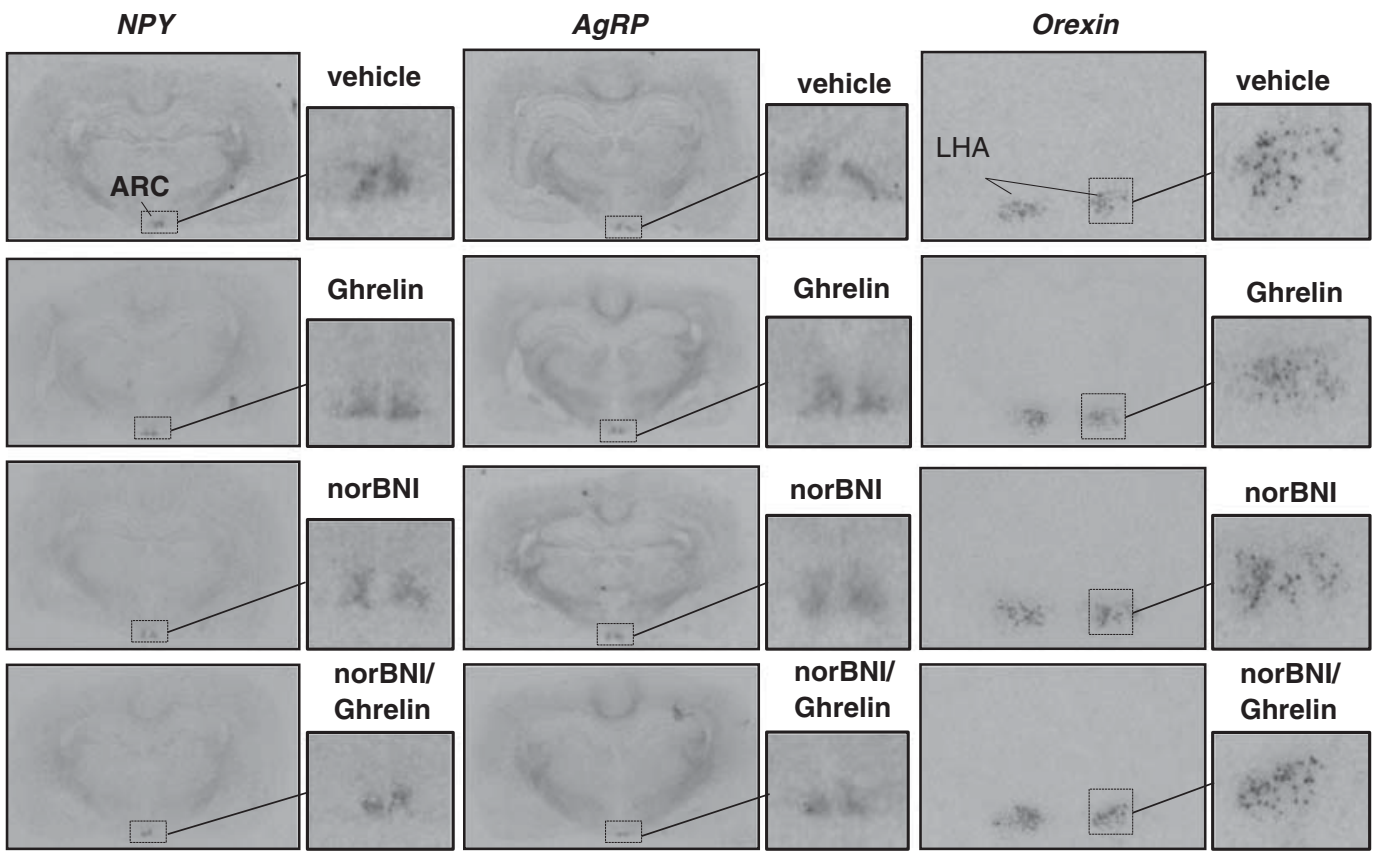

Figure 3 Study of food intake and hypothalamic orexigenic factors under specific VTA ghrelin stimulation and blockade with norBNI. (a) Pictures representing the trajectory and placement of double VTA guide cannula. (b) Study of ghrelin-induced food intake in rats under directed VTA bilateral injection of vehicle, ghrelin $(2 \mu \mathrm{g})$, norBNI $(4 \mu \mathrm{g})$, and norBNI/ghrelin at $2 \mathrm{~h} . n=10$ per group. Two-way ANOVA indicating A = significant effect of norBNI $(P<0.000 \mathrm{I}), \mathrm{B}=$ significant effect of ghrelin $(P<0.0 \mathrm{I})$. (c) mRNA expression of orexigenic hypothalamic neuropeptides NPY, AgRP, and orexin analyzed by in situ hybridization. $n=8$ per group). Values are expressed as mean \pm SEM. 
or Orexin in the LHA between all of the groups studied (Figure 3c).

\section{ARC Oprk1, but not VTA Oprk1, Controls i.c.v. Ghrelin-Induced Food Intake}

In order to investigate which are the key neuronal populations modulating the actions of KOR on ghrelininduced food intake, we first inhibited $O p k r 1$ specifically in the ARC with an AAV encoding a shRNA Opkr1 (Figure 4a; Supplementary Figure 4D), reducing its mRNA and protein expression by $\sim 25$ and $30 \%$, respectively (Figure $4 \mathrm{~b}-\mathrm{d}$ ). However, the NPY, AgRP, and GHS-R1A mRNA expression in the ARC was unaltered in shRNA Opkr1 animals compared with the control group (Supplementary Figure $4 \mathrm{~A}$ ), indicating that ghrelin-mediated signal transduction remains intact. During 14 days after AAV injections, food intake and weight gain were similar between controls and rats that had received the shRNA Oprk1 AAV in the ARC (Supplementary Figure 4B and C). After 14 days, rats were treated i.c.v. with vehicle or ghrelin. While control rats treated with ghrelin showed a marked hyperphagia during the 2 -h period post-injection $\left(p_{\text {ghrelin }}<0.0001\right.$, $\mathrm{F}=61.21, \mathrm{DF}=1)$, rats with genetic silencing of Oprk1 specifically in the ARC no longer showed an orexigenic response to i.c.v. ghrelin (Figure 4e), and we observed a significant interaction between Oprk1 genetic silencing and ghrelin's orexigenic effect ( $p_{\text {interaction }}=0.0038, F=9.899$, $\mathrm{DF}=1$ ). In order to test the specificity of the AAV encoding a shRNA Opkr1, we studied if KOR knockdown in the ARC attenuated DAMGO-induced hyperphagia. We observed a significant increase in food intake at $2 \mathrm{~h}$ after i.c.v. DAMGO injection $\left(p_{\mathrm{DAMGO}}=0.0004, \mathrm{~F}=15.45, \mathrm{DF}=1\right)$ with no interaction between Oprk1 silencing and DAMGO-induced feeding at the 2 - $\mathrm{h}$ time point $\left(p_{\text {interaction }}=0.541, \mathrm{~F}=\right.$ $0.381, \mathrm{DF}=1)$ and $4 \mathrm{~h}$ after i.c.v. DAMGO injection $\left(p_{\mathrm{DAMGO}}<0.0001, \quad \mathrm{~F}=31.49, \quad \mathrm{DF}=1 ; \quad p_{\text {interaction }}=0.551\right.$, $\mathrm{F}=0.36, \mathrm{DF}=1)($ Figure $4 \mathrm{f})$.

Next, we inhibited Opkr1 specifically in the VTA (Figure 4g; Supplementary Figure 5D) reducing its mRNA and protein expression by $\sim 25$ and $60 \%$, respectively (Figure 4h-j). GHS-R1A mRNA expression in VTA remained unaltered in shRNA Opkr1 animals compared with control group (Supplementary Figure 5A). During 14 days after AAV injections, food intake and weight gain were similar between controls and rats that had received the shRNA Oprk1 AAV in VTA (Supplementary Figure 5B and C). After 14 days, i.c.v. ghrelin increased feeding in both controls and shRNA Oprk1 rats $\left(p_{\text {ghrelin }}=0.011, \mathrm{~F}=7.38\right.$, $\mathrm{DF}=1$ ) and no interaction was detected between Oprk1 genetic silencing and ghrelin orexigenic effect $\left(p_{\text {interaction }}=0.832, \mathrm{~F}=0.045, \mathrm{DF}=1\right)$ (Figure $\left.4 \mathrm{k}\right)$. On the other hand, KOR protein levels remained unchanged in the lateral hypothalamus (LH) when the AAV encoding a shRNA Opkr1 was injected into the ARC or VTA (Figure 4l), indicating a specific silencing of Oprk1 in the areas specifically targeted by the AAV.

\section{Ghrelin and KOR Signaling Regulate Food Motivation}

The previously reported effects of ghrelin on food motivated behavior (lever-pressing for a sucrose reward in a progres- sive ratio operant responding paradigm (Skibicka et al, 2012) was confirmed in the current study ( $p_{\text {ghrelin }}<0.0001$, $\mathrm{F}=19.17, \mathrm{DF}=1$ ) (Figure 5). We also found that norBNI significantly decreased sucrose reward $\left(p_{\text {norBNI }}=0.0028\right.$, $\mathrm{F}=6.34, \mathrm{DF}=1)$, although the $P$-value for interaction did not reach statistical significance $\left(p_{\text {norBNI:ghrelin }}=0.1\right.$, $\mathrm{F}=1.691, \mathrm{DF}=1)($ Figure 5$)$.

\section{DISCUSSION}

Opioids are involved in a broadly distributed neural network, including especially reward areas involved in non-homeostatic (hedonic) food intake and reward. The acquisition of hedonic feeding appears to involve activation of the mesolimbic dopamine system, involving a dopaminergic projection from the VTA to the NAcc. Endogenous opioids regulate the mesolimbic dopamine projection at both the level of the VTA and the NAcc, providing a potential mechanism by which opioids may alter hedonic feeding. Additionally, there are indications that hypothalamic opioid receptor signaling may also be of importance for food intake that is driven by energy deficit. For instance, blockade of opioid receptors influences the orexigenic effects of NPY (Kotz et al, 1993) and AgRP (Hagan et al, 2001). Although these studies suggest that the hypothalamic opioid system plays an important role in the modulation of hedonic and homeostatic pathways controlling food intake, the molecular mechanisms and neural substrates that govern these actions remain poorly understood.

Ghrelin is a stomach-derived hormone that increases food intake (Nakazato et al, 2001) and adiposity (Perez-Tilve et al, 2011; Tschop et al, 2000) and modulates stress-based eating (Chuang et al, 2011). For its orexigenic action, ghrelin requires GHS-R1A, which is expressed in NPY/AgRP neurons in the hypothalamic ARC (Wren et al, 2000). After the activation of the GHS-R1A, the cellular response to ghrelin activates hypothalamic SIRT1 (Dietrich et al, 2010; Velasquez et al, 2011), which deacetylates p53, leading to increased phosphorylated levels of AMPK and to the further inactivation of enzymatic steps of the novo fatty acid biosynthetic pathway in the $\mathrm{VMH}$ and subsequent activation of the fatty acid oxidation (Lopez et al, 2008). These molecular events induce changes in UCP2 and reactive oxygen species (ROS) (Andrews et al, 2008), and the upregulation of the transcription factors Bsx (Sakkou et al, 2007), FoxO1, and pCREB (Lopez et al, 2010). The activation of these transcription factors leads to the ultimate step that includes the increased transcription rate of NPY and AgRP (Wren et al, 2000). In the present study, we provide evidence that central ghrelin administration activates an alternative signal transduction pathway that is independent of hypothalamic SIRT1/AMPK/fatty acid metabolism and involves the KOR signaling system. Interestingly, we found that KOR and GHS-R1A are co-localized in hypothalamic areas implicated in the regulation of food intake.

Dynorphin, the endogenous ligand of KOR, stimulates feeding in various species. Our results show that proDyn increased in the ARC and PVH at $2 \mathrm{~h}$ after central ghrelin administration. Consistent with this, chronic central ghrelin treatment to rats has also been shown to increase hypothalamic proDyn gene expression (Salome et al, 
2009). Moreover, mice lacking dynorphin showed a reduced expression of NPY in the ARC (Sainsbury et al, 2007; Wittmann et al, 2009). Collectively, these studies suggest that hypothalamic proDyn-derived peptides may control the expression of orexigenic pathways. Consistent with an interaction between ghrelin and the proDyn/KOR system, we found that pharmacological inhibition of KOR blunted ghrelin-induced food intake by around 70\%. Unexpectedly, the molecular underpinnings responsible for this interaction were independent of ghrelin-induced AMPK activation. a

Control ARC-vehicle i.c.v.

$\square$ Control ARC-Ghrelin i.c.v. $(5 \mu \mathrm{g})$

$\square$ shRNA Oprk1 ARC-vehicle i.c.v.

$\square$ shRNA Oprk1 ARC-Ghrelin i.c.v.

e

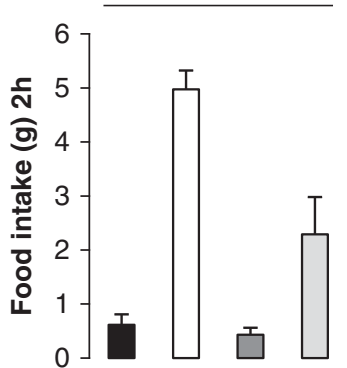

g

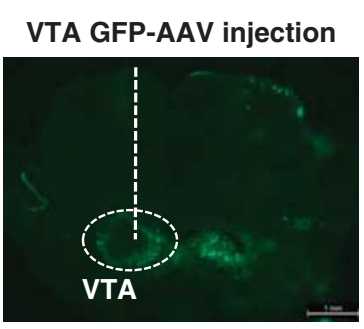

Control VTA-Saline i.c.v.

$\square$ Control VTA-Ghrelin i.c.v. $(5 \mu \mathrm{g})$

$\square$ shRNA Oprk1 VTA-Saline i.c.v.

$\square$ shRNA Oprk1 VTA-Ghrelin i.c.v.

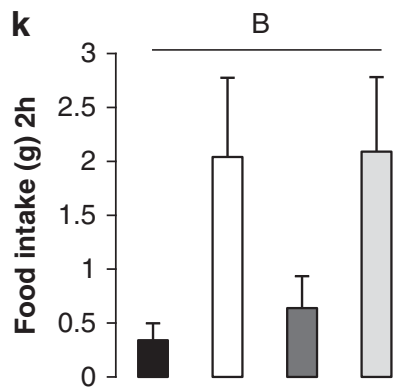

b

f

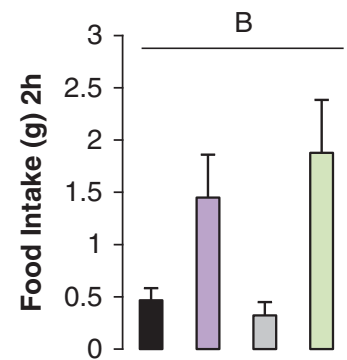

h

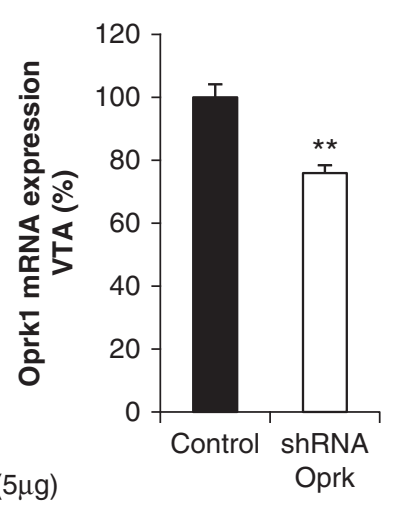

c
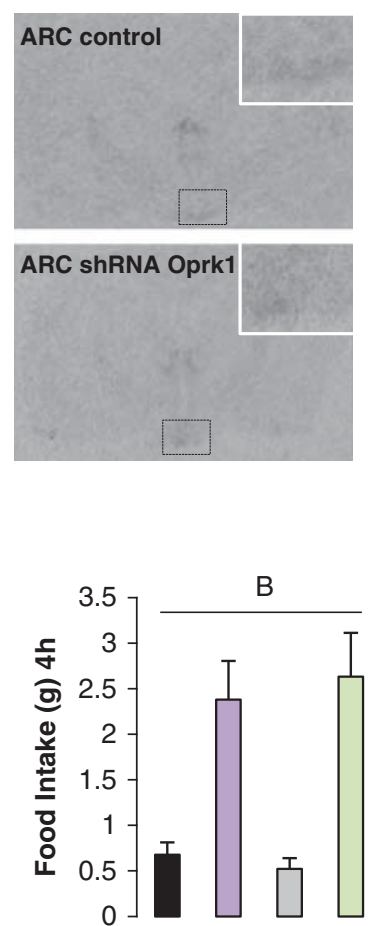

i

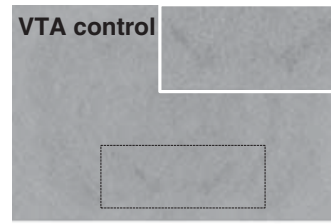

VTA shRNA

Oprk1

ARC
Control shRNA Oprk

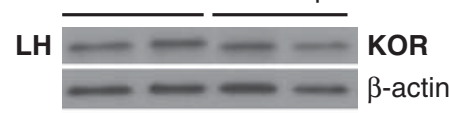

VTA

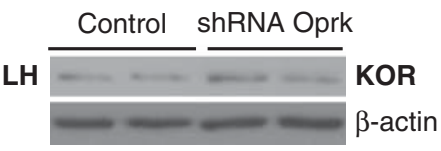

d
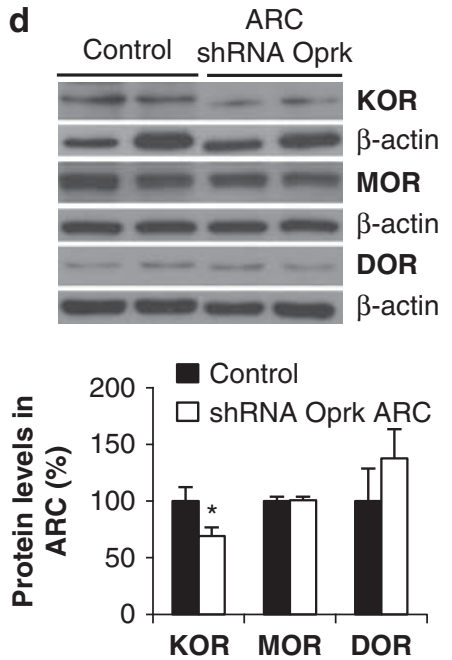

Control ARC-vehicle i.c.v.

$\square$ Control ARC-DAMGO i.c.v. (10 nmol)

$\square$ shRNA Oprk1 ARC-vehicle i.c.v.

$\square$ shRNA Oprk1 ARC-DAMGO i.c.v.
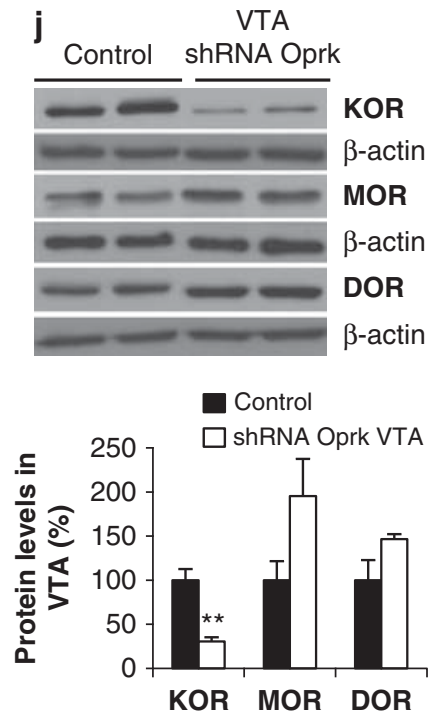

KOR MOR DOR

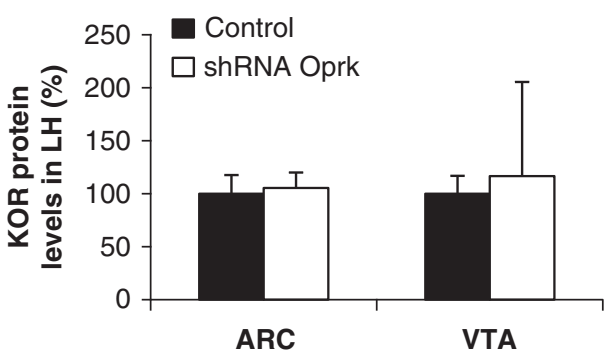


While AMPK remained activated, the increased levels of key transcription factors (Bsx, pCREB) and orexigenic neuropeptide $\mathrm{Y}$ in the ghrelin signaling pathway were reduced when KOR was blocked with norBNI. Therefore, our results demonstrate the existence of a novel mechanism for the orexigenic action of ghrelin in hypothalamus.

Based on previous studies and the wide distribution of GHS-R1A and KOR, it seems reasonable to hypothesize that KOR may regulate the orexigenic action of ghrelin through multiple feeding systems. Stimulation of both KOR (Glass et al, 1999; Stanley et al, 1988) and GHS-R1A (Abizaid et al, 2006) within the VTA modulates the activity of dopamine neurons to promote appetite. Although pharmacological suppression of KOR and ghrelin injection specifically in the VTA modified feeding behavior, our results failed to find a significant interaction between ghrelin and norBNI on food intake at the level of the VTA. Importantly, the mechanisms utilized by ghrelin within the VTA to modulate feeding did not involve the classic homeostatic pathways stimulated by ghrelin, since both NPY and AgRP levels remained unchanged after the intra-VTA injections. The fact that intra-VTA injections of ghrelin did not affect hypothalamic pathways supports the hypothesis that ghrelin activates two parallel and divergent pathways to increase food intake, one originating in the hypothalamus and engaging hypothala-

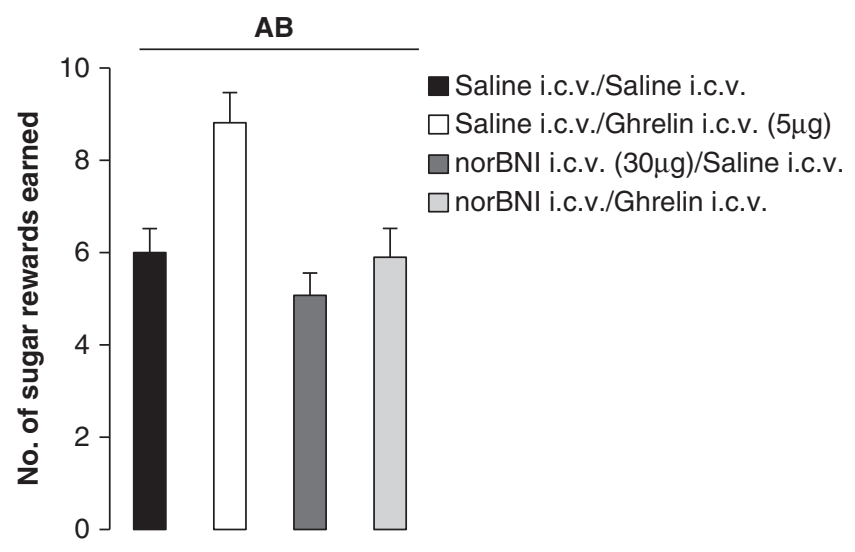

Figure 5 Effects of KOR blockade and ghrelin injection on food reward behavior. Number of sugar rewards earned. Values are shown as mean \pm SEM, $n=10-16$ rats per group; $A=$ significant effect of norBNI $(P<0.00 \mathrm{I}), \quad B=$ significant effect of ghrelin $(P<0.0 \mathrm{I})$ using two-way ANOVA. mic NPY/AgRP and the other originating in the VTA and engaging the dopamine system.

Consistent with the effects of ghrelin and KOR at the level of the VTA, we found that ghrelin increased food reward and motivation whereas a KOR antagonist suppressed them, an effect tightly linked to the mesolimbic dopamine system. Although our results seem to indicate that pharmacological central suppression of KOR attenuated ghrelin's effects on lever-pressing for a sugar reward in a progressive ratio schedule, a two-way ANOVA test failed to find a significant interaction between ghrelin and norBNI. This statistical analysis seems to indicate that ghrelin does not require the KOR for food reward behavior. However, it is important to point out that this lack of interaction could be due to the number of animals used in our experiment $(n=10-16)$, whereas the optimal statistical power for the two-way ANOVA is a $n>30$. Although KOR may not be critical for ghrelin's effects on food motivated behavior, other opioid signaling pathways appear to be involved, as evidenced by studies in which i.c.v. or intra-VTA administration of the $\mu$-preferring antagonist, naltrexone, suppressed these effects of ghrelin (when given i.c.v. or intra-VTA) (Skibicka et al, 2011b).

Next, we explored the specific hypothalamic neuronal populations responsible for the interaction between ghrelin and the proDyn/KOR pathway. Genetic downregulation of Oprk1 in ARC significantly decreased the orexigenic effect caused by i.c.v. ghrelin administration. Contrary, Oprk1 downregulation in ARC did not affect i.c.v. DAMGO-induced hyperphagia, demonstrating that the specific inhibition of KOR was responsible of the attenuation of ghrelin-induced feeding. By contrast, the inactivation of KOR by iRNA in the VTA had no effect on ghrelin-induced food intake after i.c.v. ghrelin administration. Our results suggest that for the orexigenic effects of centrally applied ghrelin, the ARC KOR population is important, whereas the VTA KOR population is not required. These data also corroborate our hypothesis that KOR signaling in the VTA does not affect hypothalamic pathways involved in energy balance regulation.

In summary, we demonstrate that the orexigenic actions of ghrelin depend, at least in part, on the hypothalamic proDyn/KOR pathway. This mechanism appears to be independent of ghrelin-induced hypothalamic AMPK activation but modulates levels of the transcription factors and orexigenic neuropeptides triggered by ghrelin (Supplementary Figure 6). These findings reveal another component of the complex pathways affected by ghrelin to control feeding behavior.

\footnotetext{
Figure 4 OprkI mRNA silencing in ARC and VTA. (a) Injection of AAV vectors encoding for a green fluorescent protein (GFP) to test a specific site of expression in ARC. Scale bars: $300 \mu \mathrm{m}$. (b) mRNA expression of Opkrl in ARC measured by real-time qPCR (b) in rats treated with AAV-shRNA Opkrl or control AAV. $n=6-8$ per group, $P<0.01$ (***) using t-Student analysis. (c) Illustration of in situ hybridization of control or AAV-shRNA Opkrl rats. (d) Protein levels of $\kappa(K O R), \mu(M O R)$, and $\delta$ (DOR) opioid receptors in rats treated with control or shRNA Opkrl-AAVs in ARC. $n=3-4$ per group. t-Student, $P<0.05(*)$. (e) Food intake analysis $2 \mathrm{~h}$ after i.c.v. injection of vehicle or ghrelin $(5 \mu \mathrm{g})$ in rats stereotaxically treated with control or AAV-shRNA Opkrl into the ARC. $n=10$ per group. A denotes significant effect of silencing mRNA Oprk I $(P<0.0 I)$, B denotes significant effect of ghrelin $(P<0.000 I)$, $C$ denotes significant gen silencing-ghrelin interaction $(P<0.0 \mathrm{I})$ using two-way ANOVA. (f) Food intake analysis $2 \mathrm{~h}$ after i.c.v. injection of vehicle or DAMGO $(10 \mathrm{nmol})$ in rats stereotaxically treated with control or AAV-shRNA Opkrl into the ARC. $n=10$ per group. B denotes significant effect of DAMGO $(P<0.00$ l for $2 \mathrm{~h}$ and $P<0.000$ I for $4 \mathrm{~h}$ ). (g) Injection of AAV vectors encoding for a green fluorescent protein (GFP) to test a specific site of expression in VTA. Scale bars: I mm. (h) mRNA expression of Opkrl in VTA measured by real-time qPCR in rats treated with control or AAV-shRNA Opkrl in VTA. $n=6-8$ per group. $t$-Student, $P<0.0 I$ (**). (i) Representation of in situ hybridization images of control or AAV-shRNA Opkrl rats. (j) Protein levels of $\kappa$ (KOR), $\mu$ (MOR), and $\delta$ (DOR) opioid receptors in rats treated with control or shRNA Opkrl-AAVs in ARC. $n=3-4$ per group. $t-S t u d e n t, P<0.0$ I (***). (k) Food intake analysis $2 \mathrm{~h}$ after i.c.v. injection of vehicle or ghrelin $(5 \mu \mathrm{g})$ in rats stereotaxically treated with control or AAV-shRNA Opkrl into the VTA. $n=10$ per group. B denotes significant effect of ghrelin $(P<0.05)$ using two-way ANOVA. (I) KOR protein expression analysis in lateral hypothalamus (LH) of control and AAV-shRNA Oprkl rats injected into the ARC and the VTA. $n=4$ per group. Values are expressed as mean \pm SEM.
} 


\section{ACKNOWLEDGEMENTS}

We thank Luz Casas and Ana Senra, at the University of Santiago de Compostela, for helping with in situ hybridization and immunofluorescence techniques. The research leading to these results received funding from the European Community, primarily grant agreement FP7-KBBE-2009-3245009 (CD, SLD, and RAHA) but also ERC-2011-StGOBESITY53-281408 (RN), and FP7-KBBE-2010-4-266408. The research was also supported by Ministerio de Educacion y Ciencia (CD: BFU2011-02001; ML: RyC-2007-00211; RN: RYC-2008-02219 and SAF2009-07049; Xunta de Galicia (ML: 10PXIB208164PR, RN: 2010/14 and 2012-CP069), Fondo Investigationes Sanitarias (ML: PS09/01880), CIBER de Fisiopatología de la Obesidad y Nutrición is an initiative of ISCIII. SLD was also supported by the Swedish Research Council for Medicine (2009-S266) and FOU/ALF Göteborg (ALFGBG-138741).

\section{DISCLOSURE}

The authors declare no conflict of interest.

\section{REFERENCES}

Abizaid A, Liu ZW, Andrews ZB, Shanabrough M, Borok E, Elsworth JD et al (2006). Ghrelin modulates the activity and synaptic input organization of midbrain dopamine neurons while promoting appetite. J Clin Invest 116: 3229-3239.

Andrews ZB, Liu ZW, Walllingford N, Erion DM, Borok E, Friedman JM et al (2008). UCP2 mediates ghrelin's action on NPY/AgRP neurons by lowering free radicals. Nature 454: 846-851.

Arvidsson U, Riedl M, Chakrabarti S, Vulchanova L, Lee JH, Nakano AH et al (1995). The kappa-opioid receptor is primarily postsynaptic: combined immunohistochemical localization of the receptor and endogenous opioids. Proc Natl Acad Sci USA 92: 5062-5066.

Czyzyk TA, Nogueiras R, Lockwood JF, McKinzie JH, Coskun T, Pintar JE et al (2010). kappa-Opioid receptors control the metabolic response to a high-energy diet in mice. FASEB J 24: 1151-1159.

Czyzyk TA, Romero-Pico A, Pintar J, McKinzie JH, Tschop MH, Statnick MA et al (2012). Mice lacking delta-opioid receptors resist the development of diet-induced obesity. FASEB J 26: 3483-3492.

Chavkin C, James IF, Goldstein A (1982). Dynorphin is a specific endogenous ligand of the kappa opioid receptor. Science 215: 413-415.

Chuang JC, Perello M, Sakata I, Osborne-Lawrence S, Savitt JM, Lutter $\mathrm{M}$ et al (2011). Ghrelin mediates stress-induced foodreward behavior in mice. J Clin Invest 121: 2684-2692.

de Backer MW, Brans MA, van Rozen AJ, van der Zwaal EM, Luijendijk MC, Garner KG et al (2010). Suppressor of cytokine signaling 3 knockdown in the mediobasal hypothalamus: counterintuitive effects on energy balance. J Mol Endocrinol 45: 341-353.

DePaoli AM, Bell GI, Stoffel M (1994). G protein-activated inwardly rectifying potassium channel (GIRK1/KGA) mRNA in adult rat heart and brain by in situ hybridization histochemistry. Mol Cell Neurosci 5: 515-522.

Dietrich MO, Antunes C, Geliang G, Liu ZW, Borok E, Nie Y et al (2010). Agrp neurons mediate Sirtl's action on the melanocortin system and energy balance: roles for Sirt1 in neuronal firing and synaptic plasticity. J Neurosci 30: 11815-11825.
Egecioglu E, Jerlhag E, Salome N, Skibicka KP, Haage D, Bohlooly YM et al (2010). Ghrelin increases intake of rewarding food in rodents. Addict Biol 15: 304-311.

Glass MJ, Billington CJ, Levine AS (1999). Opioids and food intake: distributed functional neural pathways? Neuropeptides 33: 360368.

Greenway FL, Fujioka K, Plodkowski RA, Mudaliar S, Guttadauria M, Erickson J et al (2010). Effect of naltrexone plus bupropion on weight loss in overweight and obese adults (COR-I): a multicentre, randomised, double-blind, placebo-controlled, phase 3 trial. Lancet 376: 595-605.

Hagan MM, Rushing PA, Benoit SC, Woods SC, Seeley RJ (2001). Opioid receptor involvement in the effect of AgRP- (83-132) on food intake and food selection. Am J Physiol Regul Integr Comp Physiol 280: R814-R821.

Horan P, Taylor J, Yamamura HI, Porreca F (1992). Extremely long-lasting antagonistic actions of nor-binaltorphimine (norBNI) in the mouse tail-flick test. J Pharmacol Exp Ther 260: 1237-1243.

Johnstone LE, Fong TM, Leng G (2006). Neuronal activation in the hypothalamus and brainstem during feeding in rats. Cell Metab 4: 313-321.

Kola B, Hubina E, Tucci SA, Kirkham TC, Garcia EA, Mitchell SE et al (2005). Cannabinoids and ghrelin have both central and peripheral metabolic and cardiac effects via AMP-activated protein kinase. J Biol Chem 280: 25196-25201.

Kotz CM, Grace MK, Billington CJ, Levine AS (1993). The effect of norbinaltorphimine, beta-funaltrexamine and naltrindole on NPY-induced feeding. Brain Res 631: 325-328.

Lambert PD, Wilding JP, al-Dokhayel AA, Gilbey SG, Bloom SR (1993). The effect of central blockade of kappa-opioid receptors on neuropeptide Y-induced feeding in the rat. Brain Res 629: 146-148.

Lopez M, Lage R, Saha AK, Perez-Tilve D, Vazquez MJ, Varela L et al (2008). Hypothalamic fatty acid metabolism mediates the orexigenic action of ghrelin. Cell Metab 7: 389-399.

Lopez M, Seoane L, Garcia MC, Lago F, Casanueva FF, Senaris R et al (2000). Leptin regulation of prepro-orexin and orexin receptor mRNA levels in the hypothalamus. Biochem Biophys Res Commun 269: 41-45.

Lopez M, Varela L, Vazquez MJ, Rodriguez-Cuenca S, Gonzalez CR, Velagapudi VR et al (2010). Hypothalamic AMPK and fatty acid metabolism mediate thyroid regulation of energy balance. Nat Med 16: 1001-1008.

Mansour A, Fox CA, Burke S, Meng F, Thompson RC, Akil H et al (1994). Mu, delta, and kappa opioid receptor mRNA expression in the rat CNS: an in situ hybridization study. J Comp Neurol 350: 412-438.

Morley JE, Levine AS (1983). Involvement of dynorphin and the kappa opioid receptor in feeding. Peptides 4: 797-800.

Nakazato M, Murakami N, Date Y, Kojima M, Matsuo H, Kangawa $\mathrm{K}$ et al (2001). A role for ghrelin in the central regulation of feeding. Nature 409: 194-198.

Naleid AM, Grace MK, Cummings DE, Levine AS (2005). Ghrelin induces feeding in the mesolimbic reward pathway between the ventral tegmental area and the nucleus accumbens. Peptides 26: 2274-2279.

Nogueiras R, Lopez M, Lage R, Perez-Tilve D, Pfluger P, MendietaZeron $\mathrm{H}$ et al (2008). Bsx, a novel hypothalamic factor linking feeding with locomotor activity, is regulated by energy availability. Endocrinology 149: 3009-3015.

Nogueiras R, Wiedmer P, Perez-Tilve D, Veyrat-Durebex C, Keogh JM, Sutton GM et al (2007). The central melanocortin system directly controls peripheral lipid metabolism. J Clin Invest 117: 3475-3488.

Ogata R, Matsuzaki T, Iwasa T, Kiyokawa M, Tanaka N, Kuwahara A et al (2009). Hypothalamic Ghrelin suppresses pulsatile 
secretion of luteinizing hormone via beta-endorphin in ovariectomized rats. Neuroendocrinology 90: 364-370.

Perez-Tilve D, Heppner K, Kirchner H, Lockie SH, Woods SC, Smiley DL et al (2011). Ghrelin-induced adiposity is independent of orexigenic effects. FASEB J 25: 2814-2822.

Ragnauth A, Ruegg H, Bodnar RJ (1997). Evaluation of opioid receptor subtype antagonist effects in the ventral tegmental area upon food intake under deprivation, glucoprivic and palatable conditions. Brain Res 767: 8-16.

Sainsbury A, Lin S, McNamara K, Slack K, Enriquez R, Lee NJ et al (2007). Dynorphin knockout reduces fat mass and increases weight loss during fasting in mice. Mol Endocrinol 21: 17221735.

Sakkou M, Wiedmer P, Anlag K, Hamm A, Seuntjens E, Ettwiller L et al (2007). A role for brain-specific homeobox factor Bsx in the control of hyperphagia and locomotory behavior. Cell Metab 5: 450-463.

Salome N, Hansson C, Taube M, Gustafsson-Ericson L, Egecioglu E, Karlsson-Lindahl L et al (2009). On the central mechanism underlying ghrelin's chronic pro-obesity effects in rats: new insights from studies exploiting a potent ghrelin receptor (GHSR1A) antagonist. J Neuroendocrinol 21: 777-785.

Saper CB, Chou TC, Elmquist JK (2002). The need to feed: homeostatic and hedonic control of eating. Neuron 36: 199-211.

Seoane LM, Lopez M, Tovar S, Casanueva FF, Senaris R, Dieguez C (2003). Agouti-related peptide, neuropeptide Y, and somatostatin-producing neurons are targets for ghrelin actions in the rat hypothalamus. Endocrinology 144: 544-551.

Sibilia V, Lattuada N, Rapetti D, Pagani F, Vincenza D, Bulgarelli I et al (2006). Ghrelin inhibits inflammatory pain in rats: involvement of the opioid system. Neuropharmacology 51: 497-505.

Skibicka KP, Dickson SL (2011a). Ghrelin and food reward: the story of potential underlying substrates. Peptides 32: 2265-2273.
Skibicka KP, Hansson C, Alvarez-Crespo M, Friberg PA, Dickson SL (2011b). Ghrelin directly targets the ventral tegmental area to increase food motivation. Neuroscience 180: 129-137.

Skibicka KP, Hansson C, Egecioglu E, Dickson SL (2012). Role of ghrelin in food reward: impact of ghrelin on sucrose selfadministration and mesolimbic dopamine and acetylcholine receptor gene expression. Addict Biol 17: 95-107.

Skibicka KP, Shirazi RH, Hansson C, Dickson SL (2011c). Ghrelin interacts with neuropeptide $\mathrm{Y}$ Y1 and opioid receptors to increase food reward. Endocrinology 153: 1194-1205.

Stanley BG, Lanthier D, Leibowitz SF (1988). Multiple brain sites sensitive to feeding stimulation by opioid agonists: a cannulamapping study. Pharmacol Biochem Behav 31: 825-832.

Tabarin A, Diz-Chaves Y, Carmona Mdel C, Catargi B, Zorrilla EP, Roberts AJ et al (2005). Resistance to diet-induced obesity in mu-opioid receptor-deficient mice: evidence for a 'thrifty gene'. Diabetes 54: 3510-3516.

Tschop M, Smiley DL, Heiman ML (2000). Ghrelin induces adiposity in rodents. Nature 407: 908-913.

Velasquez DA, Martinez G, Romero A, Vazquez MJ, Boit KD, Dopeso-Reyes IG et al (2011). The central Sirtuin 1/p53 pathway is essential for the orexigenic action of ghrelin. Diabetes 60: $1177-1185$

Wittmann W, Schunk E, Rosskothen I, Gaburro S, Singewald N, Herzog $\mathrm{H}$ et al (2009). Prodynorphin-derived peptides are critical modulators of anxiety and regulate neurochemistry and corticosterone. Neuropsychopharmacology 34: 775-785.

Wren AM, Small CJ, Ward HL, Murphy KG, Dakin CL, Taheri S et al (2000). The novel hypothalamic peptide ghrelin stimulates food intake and growth hormone secretion. Endocrinology 141: 4325-4328.

Zigman JM, Jones JE, Lee CE, Saper CB, Elmquist JK (2006). Expression of ghrelin receptor mRNA in the rat and the mouse brain. J Comp Neurol 494: 528-548.

Supplementary Information accompanies the paper on the Neuropsychopharmacology website (http://www.nature.com/npp) 